\title{
Genomic Insight Into 21 Hypervariable Molecular Markers in The Population of Lower Himalayan Geographical Province Himachal Pradesh, India
}

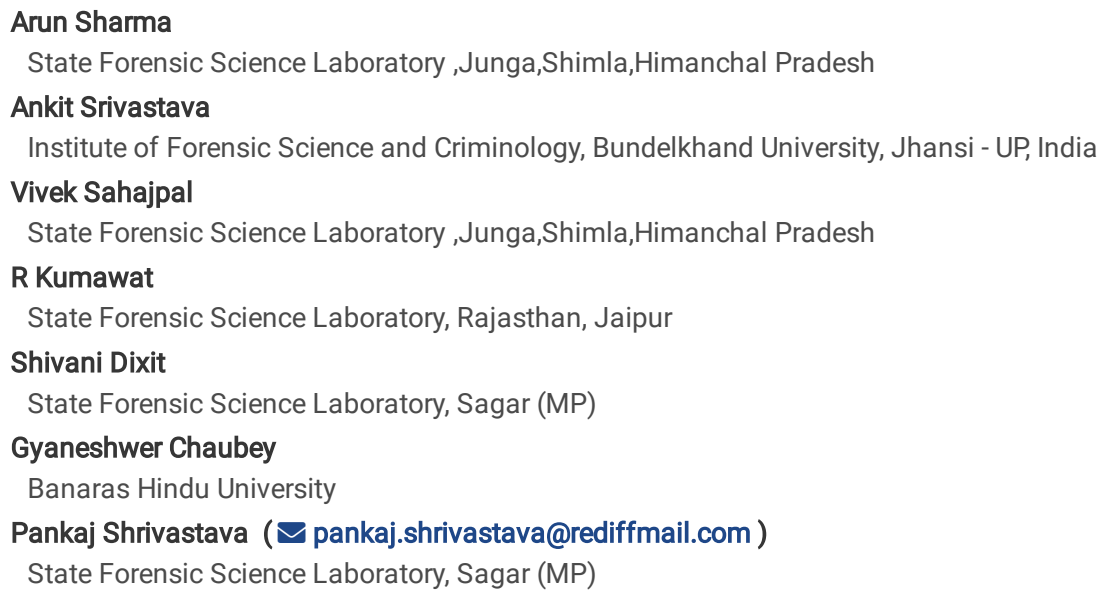




\section{Abstract}

A natural geographical barrier between Tibetan plateau and south Asian countries, the Himalayan Mountain range, serves as a natural barrier between these regions for genetic flow. This has lead to vast genomic divergence among the population residing in Indian Himalayan region..This study was designed with an aim to decipher the genomic diversity and molecular characterization of 21 hypervariable molecular markers in the population of geographical province of Himachal Pradesh in the lower Himalayan region. Randomly selected 401 unrelated individuals native of the lower Himalayan geographical region were included for this study. 21 hypervariable molecular markers included in the PowerPlex ${ }^{\circledR} 21$ system were amplified and genotyped. A total of 246 alleles and 12.3 (SE 0.927) private alleles per locus were observed. Population differentiation analysis revealed that the studied population showed a genetic affinity with the population of North India, North-west India, Central India, and Uttar Pradesh rather than the population of East India, South India, East Asia, and West Asia. Heterozygosity at the studied loci was found in the range of 0.686 to 0.920 . The unite discrimination power (PD) and exclusion power (PE) was found to be 1 and 0.999999998073765 respectively. The unite value of matching probability and typical paternity index was found to be $9.33 \times 10^{-26}$ and $5.05 \times 10^{8}$ respectively for the studied population. All the tested loci were found in Hardy Weinberg Equilibrium (HWE) expectations. Overall the studied population exhibited a great extent of genomic diversity and had a greater genetic affinity with Indo-European speakers rather than Dravidian and Tibeto-Burman speakers.

\section{Introduction:}

The Himalayan Mountain range which runs from west-northwest (Pakistan) to east-southeast (Burma) in an arch of $2400 \mathrm{~km}^{1}$ acts as a geographical barrier for gene flow between the Tibetan plateau and the South Asian subcontinent ${ }^{2}$. These geographical conditions of the Himalayan landscape lead to unique genetic characteristics in that region. The North and North-east geographical region of India lies in the foothills of the Himalayan Mountains and harbors genomic diversity in the populations of this regions ${ }^{6}$. Genomic ${ }^{3,4}$, and lingual studies ${ }^{5}$ have revealed initial settlement of modern men in the Tibetan plateau about 25000-30000 years ago ${ }^{2}$. It has been well established that India is a highly diverse country aligned in the hierarchy of caste and tribal populations and various linguistic groups ${ }^{7,8}$. Indian population's is broadly divided into Australoid, Indo-Caucasoid, Indo-Mongoloid and Negrito ethnics groups along with Indo European, Dravidian, Astro-Asiatic and Sino-Tibetan speakers ${ }^{9}$. The eastern Himalayan belt has the majority of Tibeto-Burman speakers whereas west and north-west belt has the majority of Indo European lingual family ${ }^{10}$. The genetic structure of the Indian population is broadly categorized into Ancestral North Indian (ANI) and Ancestral South Indian (ASI) population. ANI is genetically closer to the Middle East, Central Asian, and Europeans ${ }^{11}$. Several migration waves into India during the history reflected the complex genetic structure of the Indian populations. Around 4000 years ago, the last major migration wave of IndoEuropean speakers attributed to the high degree of genetic complexion ${ }^{12}$. Several genetic studies based on the Short tandem repeats (STRs) molecular markers have been reported with reference to Indian population to understand the diversity in terms of ethnicity, cultural, lingual, and geographical affinity $9,8,13$.

STRs are the highly acceptable and gold standard markers in the forensic application due to their highly polymorphic nature, heterozygosity, short sequence length along with wide distribution throughout the human genome ${ }^{14,15}$. However, mutation rates in the STR markers are higher than the single nucleotide polymorphisms (SNPs) ${ }^{16}$, but the STR markers are very useful and potential markers for the genealogical studies as well as forensic application ${ }^{17}$.

To understand the genetic diversity in the lower Himalayan geographical province Himachal Pradesh, 15 autosomal STR markers ${ }^{18}$ and 17 Y-STR marker ${ }^{19}$ have been used but it is not rationale in the terms of molecular markers and effective sample size. Therefore, the present study was undertaken to explore the genetic structure of the admixed population of the North Indian Himalayan region, Himachal Pradesh using 21 hypervariable STRs.

\section{Material And Methods:}

Samples: 401 unrelated healthy individual volunteers residing in the geographical province of Himachal Pradesh (Fig.1) were selected randomly for this study. About $1 \mathrm{ml}$ of peripheral blood was collected from these volunteers in the EDTA vials following the guideline described under the declaration of Helsinki ${ }^{20}$ and stored at $-20^{\circ} \mathrm{C}$ till further processing.

DNA Isolation: Genomic DNA was isolated from the selected samples using Phenol Chloroform Isoamyl Alcohol (PCIA) organic extraction method as described by Sambrook et al., $1989^{21}$.

DNA Quantitation: Isolated DNA was quantified with Quantifiler ${ }^{\circledR}$ Duo DNA Quantification Kit (Thermo Fisher Scientific, CA, USA) using RT-PCR 7500 platform as per recommendations of the manufacturer.

Amplification.1 ng of genomic DNA was used to amplify the 21 STR markers included in the PowerPlex® 21 system (Promega, CA, USA) using 9700 thermal cycler (Thermo Fisher Scientific, CA, USA) as per manufacturer's protocol except for $10 \mu$ reaction volume.

Genotyping: The amplified fragments were subjected to size based separation through capillary electrophoresis using Genetic Analyzer $3500 \mathrm{X}$ (Thermo Fisher Scientific, CA, USA). $1 \mu \mathrm{l}$ amplicon was diluted in the $10 \mu \mathrm{l}$ mixture volume of HiDi Formamide (Thermo Fisher Scientific, CA, USA) and WEN ILS 500 (Provided along with kit) and denatured as per recommended protocol. POP ${ }^{\mathrm{TM}}-4$ and $36 \mathrm{~cm}$ capillary array was used while running the samples on Genetic Analyzer. Allelic ladder (provided along with kit) was used to assign allele number in the DNA profile. GeneMapper ${ }^{\mathrm{TM}}$ IDX software v1.5 was used to analyze the genotyped data.

Quality control: To monitor quality parameter during the experiments, positive control (with DNA template of 2800M) and negative control (without DNA template) was used. The authors also qualified international DNA proficiency test conducted by GITAD, Spain (http://gitad.ugr.es/principal.htm). 
Statistical analysis: Allele frequency and forensic interest parameters viz., Power of discrimination (PD), Power of exclusion (PE), Polymorphic Information Contents (PIC), Matching Probability (Pm), Typical Paternity index (TPI), Observed Heterozygosity $\left(\mathrm{H}_{\text {obs }}\right.$ ), Expected Heterozygosity $\left(\mathrm{H}_{\text {exp }}\right)$, Gene Diversity (GD) and Hardy Weinberg equilibrium (HWE) test were performed using GenaAlex $6^{22}$ and STRAF statistical tool ${ }^{23}$. Population differentiation test Fst was calculated using Arlequin 3.5 software $^{24}$. Phylogenetic analysis was done with the help of POPTREE ${ }^{25}$, MEGA-6 ${ }^{26}$, and Structure2.3.4 ${ }^{27}$. Principal Coordinate Analysis (PCOA) was executed using PAST3.26 software ${ }^{28}$.

\section{Genetic data of reported populations for comparison:}

The genetic dataset of present study was compared with the dataset of reported indigenous populations viz., Balmiki (Punjab) ${ }^{29}$, Sakaldwipi Brahmin (Jharkhand) ${ }^{29}$, Konkanastha_Brahmin (Maharashtra) ${ }^{29}$, lyengar (Tamilnadu) ${ }^{29}$, Kurumans (Tamilnadu) ${ }^{29}$, Munda (Jharkhand) ${ }^{29}$, Chenchu (Andhra Pradesh) ${ }^{30}$, Lambadi (Andhra Pradesh) ${ }^{30}$, Naikpod_Gond (Andhra Pradesh) ${ }^{30}$, Yerukula (Andhra Pradesh) ${ }^{30}$, Munda (Chotanagpur) ${ }^{31}$, Santal (Chotanagpur) ${ }^{31}$, Oraon (Chotanagpur) ${ }^{31}$, Lodha (Bengal) ${ }^{32}$, Kora (Bengal) ${ }^{32}$, Maheli (Bengal) ${ }^{32}$, Central Indian Population ${ }^{33}$, Gond (MP) ${ }^{34}$, Gond_2 (MP) ${ }^{35}$, Gond_1 (MP) ${ }^{29}$, Oraon (Chhattishgarh) ${ }^{36}$, Population of Jharkhand ${ }^{37}$, Jat Sikh (Punjab) ${ }^{38}$, Baniya (Punjab) ${ }^{38}$, Khatri (Punjab) ${ }^{38}$, Population of Uttar Pradesh ${ }^{39}$, Kahar population (UP) ${ }^{40}$, Himachal Pradesh Population ${ }^{18}$, Gorkhas ${ }^{41}$, Tamil Population (Tamil Nadu) ${ }^{42}$, Population of Rajasthan ${ }^{43}$, Population of Odisha ${ }^{44}$ and Bhuiyan Population (Jharkhand) ${ }^{45}$; and global populations namely; Manchu Population of China ${ }^{46}$, Han Population of Southern China ${ }^{47}$, Tibetan Population $\left(\right.$ Nepal) ${ }^{48}$, Kathmandu ${ }^{49}$, Tibet ${ }^{49}$, Newar ${ }^{49}$, Nepalese ${ }^{50}$, Korean Population ${ }^{51}$, Royal Kingdom of Bhutan Population ${ }^{52}$, Punjabi-Pakistan ${ }^{53}$, Pashtun-Pakistan ${ }^{53}$, Sindhi- Pakistan ${ }^{53}$, Saraiki-Pakistan ${ }^{53}$, Baloch-Pakistan ${ }^{53}$ from published sources(Table 1).

Ethical approval: Written informed consent was obtained from all the participants. The study was conducted under the ethical guidelines and it was approved by the Institute Ethics Committee (Human Studies) of Maharani Laxmi Bai Medical College, Jhansi, vide letter no. 4648 dated 05.09.2020. Maharani Laxmi Bai Medical College, Jhansi is part of Bundelkhamd University, Jhansi. One of the co-author of this manuscript is posted in the same university and we took the ethical clearance on our proposal from the same Institute which is part of Bundelkhamd University, Jhansi,UP,India.

\section{Results And Discussion:}

\section{Allelic frequencies and forensic parameters:}

A total of 246 alleles were found in the studied population at all the tested loci. A total of 19 alleles were observed at the loci D1S1656 and FGA and these were the highest number of the observed alleles. At the locus TH01, lowest number of alleles were observed i.e. 6 alleles. In the currently studied highly diverse population, the mean number of alleles observed were 12.3 (SE 0.927) and mean number of effective alleles were 5.911 (SE 0.073 ) per locus. Allele frequencies ranged from 0.001 to 0.389 and allele 8 of locus TPOX was found to be the most frequent allele among all the studied loci (Table 2 ). All the loci were found under the Hardy Weinberg Equilibrium (HWE) ( $p<0.05)$. The observed heterozygosity (Hobs) ranged from 0.686 (CSF1PO) to 0.920 (D1S1656) and gene diversity (GD) varied from 0.698 (TPOX) to 0.913 (Penta E). The power of discrimination (PD) and exclusion (PE) were found in range of 0.850 (TPOX) and 0.407 (CSF1PO) to 0.984 (Penta E) and 0.837 (D1S1656) respectively. The cumulative value of discrimination (CPD) and exclusion CPE) was found to be 1 and 0.999999998073765 respectively. The matching probability $(\mathrm{Pm})$ and typical paternity index (TPI) were found in a range of $0.016(\mathrm{Penta} E)$ and 1.591 (CSF1PO) to 0.150 (TPOX) and 6.266 (D1S1656) respectively. The combined value of matching probability (coPm) and typical paternity index (coTPI) was observed as $9.33 \times 10^{-26}$ and $5.05 \times 10^{8}$ respectively for all the tested loci. An autosomal marker is considered as highly polymorphic when its discrimination power $(P D)$ value is greater than $0.80(P D>0.80)$, power of exclusion value is greater than $0.50(P E>0.50)$ and $P I C$ value is greater than $0.5(P I C>0.5) 54,55,56$. In the present study, all the loci were highly polymorphic for the studied population because the value of PIC $>0.5$. Noticeably, the locus Penta $E$ was found to be most informative in the terms of highest GD, PD, and PIC and lowest value of Pm. Locus TPOX was found to be least informative in the terms of lowest GD, $\mathrm{PD}$, and PIC and the highest value of Pm among all the tested loci (Table 3). Findings of the present study hold a prominent forensic importance as other previously reported population studies of Indo European speakers $43,57,40,39,58$, The data observed regarding the locus Penta $E$ is highly informative among all the studied loci.

\section{Interpopulation comparison:}

Allele frequencies at the common 15 STR markers of the studied population were compared with 47 populations using Nei's Da distance to draw a Phylogenetic tree. Population genetic distance Fst was calculated between studied population and other population groups based on the geographical distance as shown in Table 4. The Fst revealed higher genetic affinity between the population of Himachal Pradesh and geographically closer population groups of Uttar Pradesh, Central India, Northwest India rather than East and South India. When compared with West and East Asian populations, the population of Himachal Pradesh had 2.5 times higher genetic affinity with the West Asian than the East Asian population. The studied population had 7 times higher genetic distances with the South Indian populations in comparison with the population of central and north India (Fig. 2). This finding observed in the present study corroborates with the earlier published study wherein Indian genetic structure was broadly divided into ANI and ASI ${ }^{13}$. Moreover, the present study also indicated the presence of a small genetic pool in East India which showed a degree of genetic distance from the South, North, North-west and Central Indian genetic pool ${ }^{59,60,61}$.

\section{Phylogenetic Analysis:}

The allelic data of the studied population was compared with the 47 reported populations of India, West and East Asia at common 15 genetic markers. The Da distance was calculated by the Neighbor-Joining method using PopTree2 software. The distance was reflected in the Phylogenetic tree using MEGA-6 software. The Phylogenetic tree revealed that the population of Himachal Pradesh was most closely related with the Rajasthani and Punjabi population of Pakistan, followed by Pashtun, Sindhi, Baloch, and Saraiki populations of Pakistan, which might be results of shared ancestry(Fig. 3). In the Phylogenetic tree, 
East Indian, East Asian, and South Indian populations are depicted into the separate branches. This Phylogenetic relationship indicates the similar genetic constituents among the North, North-west, Central India, and West Asia ${ }^{62,53}$. However geographically close North and Northeast populations' viz., Nepalese, Gorkhas, Kathmandu, Tibet, Newar, Tibetan population (Nepal) showed a higher genetic affinity with the East Asian populations viz., Manchu population of China, Korean population, Royal Kingdom of Bhutan Population and Han population of Southern China rather than the population of Himachal Pradesh. The possible reason for this genetic variation could be the geographical barrier created by to the Himalayan range for the genetic flow ${ }^{2}$.

\section{Principal Coordinate Analysis (PCoA) and Heat map :}

The PCoA plot was drawn using Nei's Da distance matrix based on the allele frequencies of studied and compared 47 populations on common 15 STR markers. Euclidean similarity index was used to analyze principal coordinates, in which Coordinate 1 and 2 covered $96.301 \%$ of the variations. Due to a higher level of genetic variations, few populations viz., Chenchu (Andhra Pradesh) ${ }^{30,}$ Central Indian Population ${ }^{33}$, Jat Sikh (Punjab) ${ }^{38}$ and Kathmandu ${ }^{60}$ depicted in the outlier and resulted in clumping of most of the populations at one part of the plot (Fig. S1). To visualize genetic distance among the clumped populations, outlier populations were removed from the analysis, and the PCoA plot was redrawn (Fig. 4). Studied population clustered with the population of Himachal Pradesh ${ }^{18}$, Rajasthan followed by the populations of Pakistan viz., Punjabi ${ }^{53}$, Pashtun ${ }^{53}$, Sindhi ${ }^{53}$, Baloch ${ }^{53}$, and Saraiki ${ }^{53}$. The studied population was depicted with relative higher distance in PCoA plot with the Gorkhas, Newar, Han population of Southern China, Royal Kingdom of Bhutan Population, Tibet, Korean population, Nepalese, Tibetan population (Nepal) and Manchu population of China. The studied population had a relatively higher genetic distance with the Lodha, Kora, Maheli populations of East Indian geographical province Bengal than the populations of close geographical state Uttar Pradesh, Madhya Pradesh, Punjab, Jharkhand.

The genetic distances between the studied and compared 47 Indian and Asian populations were exemplified in the heat map (Fig. 5), which revealed a similar fashion of genetic relatedness as illustrated in Phylogenetic tree and Principal Coordinate Analysis.

\section{Structure Analysis:}

To examine the genetic similarity and differentiation between the studied population and 5 populations of Pakistan, 16 populations of East and South-East Asia, 3 populations of Bangladesh along with 12 populations of India were subjected to structure analysis at the common 15 autosomal STR markers. The inferred cluster k ranged from 2 to 10 with 20 repetitions after a 100,000 burn in period and 100,000 MCMC simulations for each k. $\mathrm{k}$ and estimated log probability data statistics were evaluated using Structure Harvester ${ }^{63}$ for the selection of most suitable configured $\mathrm{K}$. Cluster 4 ( $\mathrm{K}=4$ ) was found in the informative shared ancestry component among the studied and compared populations. The ancestry component (Yellow color) was found most prevalent in the North-west Indian populations viz., Gujjar ${ }^{64}$, Meena ${ }^{64}$, Kahar population of Uttar Pradesh, admixed populations of Uttar Pradesh, Rajasthan ${ }^{64}$, Madhya Pradesh, Jharkhand similar to ANI61,65; and Pakistani populations (Balochi, Brahui, Sindhi, Pathan, and Burusho)(Fig. 6).The ancestry component (Green color) was found concentrated among the East Asian related populations (Cambodian, Han, Dai, Daur, Hezhen, Lahu, Miaozu, Orogen, She, Tujia, Tu, Xibo, Yizu, Mangola, Nexi, Japanese, Chakma,Marma,Tripura, and Bengali). The dark blue color depicted that the ancestry component was most prevalent in the Dravidian speakers (Madiga, Adi, kapu) similar to $A \mathrm{SI}^{61,65}$. The light blue color depicted an ancestry component found in a loose gradient from west to east Asian populations. Overall most of the ancestry component was found in an east-west gradient along with geography. The ancestry component of the studied population was found in homogeneity with the geographically close populations of North, Northwest, Central India and population of Pakistan.

\section{Conclusion}

This study provides a genetic evidence for an unique gene pool among the North, North-west, Central Indian populations which significantly differed from the East and South Indian genetic pool. The findings of the population differentiations, Phylogenetic relatedness, PCoA, a Heat map, and structure analysis revealed that the studied population showed gradient gene flow towards West rather than South and East Indian populations. The studied 21 STR markers were found to be highly useful for the population genetics as well as population migration study. The dataset of this study will be of wide use in the preview of the recently introduced "The DNA technology (use and application) regulation bill 2019. It will enrich the existence of an autosomal STR Indian DNA database.

\section{Declarations}

\section{Acknowledgments}

We are thankful to the Director, State Forensic Science Laboratory, Sagar, M.P., for extending the Genotyping facility to accomplish the study. The authors acknowledge Promega (India) for providing PowerPlerx ${ }^{(R)} 21$ system kit for this study.

\section{Author contributions}

Shrivastava P. designed the study. Sharma A and Srivastava A. collected samples and Shrivastava P. did experimental work. Kumawat R.K. performed data evaluation, statistical analysis, and wrote the manuscript. Sharma A., Sahajpal V., Dixit S. and Chaubey G. reviewed the manuscript. All authors reviewed and approved the manuscript.

\section{Competing interests}

The authors declared that they have no competing interests.

\section{Additional information}


Supplementary information is available for this paper at

Correspondence and requests for materials should be addressed to P.S.

Reprints and permissions information is available at

\section{References}

1. Treloar P.J., Coward M.P., Chambers A.F., Izatt C.N., J. K. C. Thrust geometries, interferences and rotations in the Northwest Himalaya. (Springer, 1992). doi:doi.org/10.1007/978-94-011-3066-0_30.

2. Gayden, T. et al. The Himalayas as a directional barrier to gene flow. Am. J. Hum. Genet.80, 884-894 (2007).

3. Su, B. et al. Y chromosome haplotypes reveal prehistorical migrations to the Himalayas. Hum. Genet.107, 582-590 (2000).

4. Su, B. et al. Y-Chromosome evidence for a northward migration of modern humans into Eastern Asia during the last Ice Age. Am. J. Hum. Genet.65, 17181724 (1999).

5. Van Driem, G. Languages of the Himalayas: an ethnolinguistic handbook of the greater Himalayan region. vol. 2 (Brill, 2001).

6. Kashyap, V. K., Guha, S. \& Trivedi, R. Concordance study on 15 STR loci in three major populations of Himalayan State Sikkim. J. Forensic Sci.47, 1-5 (2002).

7. Singh, K. S. India's communities. People India Natl. Ser. (1998).

8. Basu, A. et al. Ethnic India: a genomic view, with special reference to peopling and structure. Genome Res.13, 2277-2290 (2003).

9. Kashyap, V. K. et al. Genetic structure of Indian populations based on fifteen autosomal microsatellite loci. BMC Genet.7, 28 (2006).

10. Van Driem, G. Trans-Himalayan. Trans-Himalayan Linguist.266, 11-40 (2014).

11. Reich, D., Thangaraj, K., Patterson, N., Price, A. L. \& Singh, L. Reconstructing Indian population history. Nature461, 489 (2009).

12. Gadgil M, Joshi NV, Shambu Prasad UV, Manoharan S, P. S. peopling of India. (Universities Press, Hyderabad, (India), 1997).

13. Basu, A., Sarkar-Roy, N. \& Majumder, P. P. Genomic reconstruction of the history of extant populations of India reveals five distinct ancestral components and a complex structure. Proc. Natl. Acad. Sci.113, 1594-1599 (2016).

14. Ellegren, H. Microsatellites: simple sequences with complex evolution. Nat. Rev. Genet.5, 435-445 (2004).

15. Willems, T. et al. The landscape of human STR variation. Genome Res.24, 1894-1904 (2014).

16. Sun, J. X. et al. A direct characterization of human mutation based on microsatellites. Nat. Genet.44, 1161-1165 (2012).

17. Phillips, C. et al. Global patterns of STR sequence variation: sequencing the CEPH human genome diversity panel for 58 forensic STRs using the Illumina ForenSeq DNA Signature Prep Kit. Electrophoresis39, 2708-2724 (2018).

18. Mohapatra, B. K. et al. A genomic exploration of 15 autosomal STR loci for establishment of a DNA profile database of the population of Himachal Pradesh. Leg. Med. 101719 (2020).

19. Mohapatra, B. K. et al. Haplotype data for 17 Y-STR loci in the population of Himachal Pradesh, India. Int. J. Legal Med. 7-8 (2019) doi:10.1007/s00414019-02080-7.

20. Rickham, P. P. Human experimentation. Code of ethics of the world medical association. Declaration of Helsinki. Br. Med. J.2, 177 (1964).

21. Sambrook, J., Fritsch, E. F. \& Maniatis, T. Molecular cloning: a laboratory manual. (Cold Spring Harbor Laboratory Press, 1989).

22. Peakall, R. O. D. \& Smouse, P. E. GENALEX 6: genetic analysis in Excel. Population genetic software for teaching and research. Mol. Ecol. Resour.6, 288295 (2006).

23. Gouy, A. \& Zieger, M. STRAF-a convenient online tool for STR data evaluation in forensic genetics. Forensic Sci. Int. Genet.30, 148-151 (2017).

24. Excoffier, L. \& Lischer, H. E. L. Arlequin suite ver 3.5: a new series of programs to perform population genetics analyses under Linux and Windows. Mol. Ecol. Resour.10, 564-567 (2010).

25. Takezaki, N., Nei, M. \& Tamura, K. POPTREE2: Software for constructing population trees from allele frequency data and computing other population statistics with Windows interface. Mol. Biol. Evol.27, 747-752 (2009).

26. Tamura, K., Stecher, G., Peterson, D., Filipski, A. \& Kumar, S. MEGA6: molecular evolutionary genetics analysis version 6.0. Mol. Biol. Evol.30, 2725-2729 (2013).

27. Evanno, G., Regnaut, S. \& Goudet, J. Detecting the number of clusters of individuals using the software STRUCTURE: a simulation study. Mol. Ecol.14, 2611-2620 (2005).

28. Hammer, Ø., Harper, D. A. T. \& Ryan, P. D. PAST: paleontological statistics software package for education and data analysis. Palaeontol. Electron.4, 9 (2001).

29. Ghosh, T. et al. Genetic diversity of autosomal STRs in eleven populations of India. Forensic Sci. Int. Genet.5, 259-261 (2011).

30. Hima Bindu, G., Trivedi, R. \& Kashyap, V. K. Genotypic polymorphisms at fifteen tetranucleotides and two pentanucleotide repeat loci in four tribal populations of Andhra Pradesh, southern India. J Forensic Sci50, 978-983 (2005).

31. Banerjee, J., Trivedi, R. \& Kashyap, V. K. Polymorphism at 15 Short Tandem Repeat AmpFeSTR® Identifiler ${ }^{\mathrm{TM}}$ Loci in Three Aboriginal Populations of India: An Assessment in Human Identification. J. Forensic Sci.50, JFS2005151-6 (2005).

32. Singh, A., Trivedi, R. \& Kashyap, V. K. Genetic polymorphism at 15 tetrameric short tandem repeat loci in four aboriginal tribal populations of Bengal. J. Forensic Sci.51, 183-187 (2006). 
33. Shrivastava, P., Jain, T. \& Trivedi, V. Ben. Genetic polymorphism study at 15 autosomal locus in central Indian population. Springerplus4, 566 (2015).

34. Dubey, B., Meganathan, P. R., Eaaswarkhanth, M., Vasulu, T. S. \& Haque, I. Forensic STR profile of two endogamous populations of Madhya Pradesh, India. Leg. Med.11, 41-44 (2009).

35. Shrivastava, P., Jain, T. \& Trivedi, V. Ben. Structure and genetic relationship of five populations from central India based on 15 autosomal STR loci. Annals of Human Biology vol. 44 (2017).

36. Shrivastava, P., Jain, T. \& Trivedi, V. B. A genetic portrait of Oraon Indian tribe drawn with 15 autosomal and 17 Y chromosomal STR markers. Int. J. Legal Med.130, 1185-1186 (2016).

37. Imam, J., Reyaz, R., Singh, R. S., Bapuly, A. K. \& Shrivastava, P. Genomic portrait of population of Jharkhand, India, drawn with 15 autosomal STRs and 17 Y-STRs. Int. J. Legal Med.132, 139-140 (2018).

38. Giroti, R. \& Talwar, I. Diversity and differentiation in Khatris, Banias and Jat Sikhs of Punjab: a study with forensic microsatellites. Ind J Phys Anthr. Hum Genet32, 309-328 (2013).

39. Srivastava, A. et al. Genetic data for PowerPlex $21^{\mathrm{TM}}$ autosomal and PowerPlex 23 Y-STR ${ }^{\mathrm{TM}}$ loci from population of the state of Uttar Pradesh, India. Int. J. Legal Med. 1-3 (2019).

40. Batham, M. S., Kushwaha, K. P. S., Chauhan, T., Kumawat, R. K. \& Shrivastava, P. Autosomal STR allele frequencies in Kahars of Uttar Pradesh, India, drawn with PowerPlex® 21 multiplex system. Int. J. Legal Med. 1-3 (2019).

41. Preet, K. et al. Genetic Diversity in Gorkhas: An Autosomal STR Study. Sci. Rep.6, 1-9 (2016).

42. Balamurugan, K. et al. Genetic variation of 15 autosomal microsatellite loci in a Tamil population from Tamil Nadu, Southern India. Leg. Med.12, 320323 (2010).

43. R. K. Kumawat, Pankaj Shrivastava, Divya Shrivastava, G.K. Mathur, and S. D. Genomic Blueprint of Population of Rajasthan based on Autosomal STR Markers. Ann. Hum. Biol.0, 1-6 (2019).

44. Sahoo, S. et al. Genomic portrait of Odisha, India drawn by using 21 autosomal STR markers. Int. J. Legal Med. 1-3 (2020).

45. Kumar, G. et al. Estimating genetic polymorphism in Bhuiyan population of eastern India using 20 autosomal STR loci. Int. J. Legal Med. 1-3 (2020).

46. Liu, J. et al. Allele frequencies of 19 autosomal STR loci in Manchu population of China with phylogenetic structure among worldwide populations. Gene529, 282-287 (2013).

47. Tong, D. et al. Polymorphism analysis and evaluation of 19 STR loci in the Han population of Southern China. Ann. Hum. Biol.40, 191-196 (2013).

48. Kido, A. et al. STR data for 15 AmpFLSTR Identifiler loci in a Tibetan population (Nepal). Int. Congr. Ser.1288, 349-351 (2006).

49. Gayden, T. et al. Genetic insights into the origins of Tibeto-Burman populations in the Himalayas. J. Hum. Genet.54, 216-223 (2009).

50. Kraaijenbrink, T., van Driem, G. L., Opgenort, J.-R. M. L., Tuladhar, N. M. \& de Knijff, P. Allele frequency distribution for 21 autosomal STR loci in Nepal. Forensic Sci. Int.168, 227-231 (2007).

51. Yoo, S. Y. et al. A large population genetic study of 15 autosomal short tandem repeat loci for establishment of Korean DNA profile database. Mol. Cells32, 15-19 (2011).

52. Kraaijenbrink, T., van Driem, G. L., Tshering of Gaselô, K. \& de Knijff, P. Allele frequency distribution for 21 autosomal STR loci in Bhutan. Forensic Sci. Int.170, 68-72 (2007).

53. Shan, M. A., Børsting, C. \& Morling, N. Forensic application and genetic diversity of 21 autosomal STR loci in five major population groups of Pakistan. Int. J. Legal Med. 1-3 (2020).

54. Kuang, S. Q., Zhang, Y. Z. \& Chen, Z. A powerful tool for genome scanning and gene mapping of inherited disease. Genet14, 992103 (1997).

55. Shriver, M. D. et al. A novel measure of genetic distance for highly polymorphic tandem repeat loci. Mol. Biol. Evol.12, 914-920 (1995).

56. Liao, Y. et al. Genomic Portrait of Guangdong Liannan Yao Population Based on 15 Autosomal STRs and 19 Y-STRs. Sci. Rep.9, 1-6 (2019).

57. Kumar, A. et al. Genetic variation (population database) at 20 autosomal STR loci in the population of Rajasthan (north-western India). Int. J. Legal Med. 1-3 (2020).

58. Kushwaha, K. P. S., Chauhan, T., Kumawat, R. K., Dixit, S. \& Shrivastava, P. Genetic variation of 20 autosomal STRs in Jats belonging to Delhi, India. Int. J. Legal Med. 1-3 (2020).

59. Singh, S. S. et al. Evaluation of genetic link of Tharu population with South and East Asian populations. Meta Gene 100721 (2020).

60. Gayden, T. et al. Genetic insights into the origins of Tibeto-Burman populations in the Himalayas. J. Hum. Genet.54, 216-223 (2009).

61. Metspalu, M., Mondal, M. \& Chaubey, G. The genetic makings of South Asia. Curr. Opin. Genet. Dev.53, 128-133 (2018).

62. Rubab, A. et al. Population genetic portrait of Pakistani Lahore-Christians based on 32 STR loci. Sci. Rep.10, 1-8 (2020).

63. Earl, Dent A. and vonHoldt, B. M. STRUCTURE HARVESTER: a website and program for visualizing STRUCTURE output and implementing the Evanno method. Conserv. Genet. Resour.4 (2), 359-361 (2012).

64. Kumawat, R. K. et al. Peopling of Rajasthan, India: Evaluating the gene flow from east and west. Gene Reports 100990 (2020).

65. Reich, D., Thangaraj, K., Patterson, N. \& Alkes, L. Price, and Lalji Singh. 2009.“Reconstructing Indian Population History.” Nature. Ed. Summ.24,

\section{Tables}




\begin{tabular}{|c|c|c|c|c|}
\hline Sr. No. & Analysis & Population & Geographical region & Sample (n) \\
\hline \multirow[t]{42}{*}{1} & \multirow[t]{42}{*}{ Population differentiation test, phylogenetic tree, $\mathrm{PCoA}$} & Balmiki (Punjab) & \multirow[t]{34}{*}{ India } & 62 \\
\hline & & Sakaldwipi Brahmin (Jharkhand) & & 68 \\
\hline & & Konkanastha_Brahmin (Maharashtra) & & 71 \\
\hline & & lyengar (Tamilnadu) & & 67 \\
\hline & & Kurumans (Tamilnadu) & & 67 \\
\hline & & Munda (Jharkhand) & & 68 \\
\hline & & Chenchu (Andhra Pradesh) & & 100 \\
\hline & & Lambadi (Andhra Pradesh) & & 107 \\
\hline & & Naikpod_Gond (Andhra Pradesh) & & 104 \\
\hline & & Yerukula (Andhra Pradesh) & & 101 \\
\hline & & Munda (Chotanagpur) & & 128 \\
\hline & & Santal (Chotanagpur) & & 122 \\
\hline & & Oraon (Chotanagpur) & & 120 \\
\hline & & Lodha (Bengal) & & 198 \\
\hline & & Kora (Bengal) & & 118 \\
\hline & & Maheli (Bengal) & & 98 \\
\hline & & Central Indian Population & & 582 \\
\hline & & Gond (MP) & & 117 \\
\hline & & Gond_2 (MP) & & 89 \\
\hline & & Gond_1 (MP) & & 75 \\
\hline & & Oraon (Chhattishgarh) & & 103 \\
\hline & & Population of Jharkhand & & 200 \\
\hline & & Jat Sikh (Punjab) & & 52 \\
\hline & & Baniya (Punjab) & & 40 \\
\hline & & Khatri (Punjab) & & 40 \\
\hline & & Population of Uttar Pradesh & & 168 \\
\hline & & Kahar Population (UP) & & 147 \\
\hline & & Himachal Pradesh Population & & 275 \\
\hline & & Gorkhas & & 98 \\
\hline & & Tamil Population (Tamil Nadu) & & 272 \\
\hline & & Population of Rajasthan & & 317 \\
\hline & & Population of Odisha & & 508 \\
\hline & & Bhuiyan Population (Jharkhand) & & 182 \\
\hline & & Population of Himachal Pradesh & & 401 \\
\hline & & Manchu Population of China & \multirow[t]{2}{*}{ China } & 150 \\
\hline & & Han Population of Southern China & & 1161 \\
\hline & & Tibetan Population (Nepal) & \multirow[t]{5}{*}{ Nepal } & 122 \\
\hline & & Kathmandu & & 77 \\
\hline & & Tibet & & 153 \\
\hline & & Newar & & 66 \\
\hline & & Nepalese & & 953 \\
\hline & & Korean Population & Korea & 1805 \\
\hline
\end{tabular}

Page $7 / 16$ 


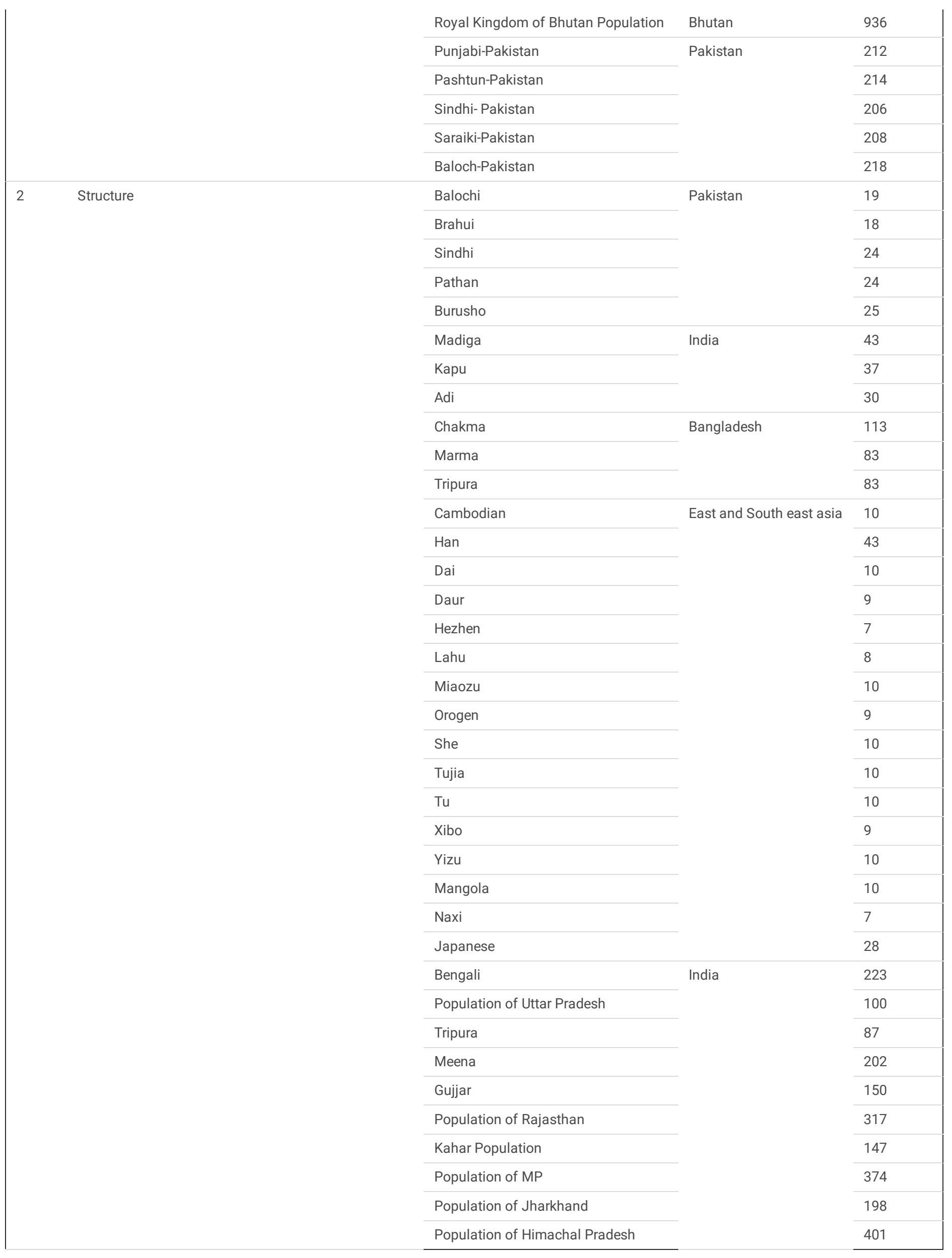

Page 8/16 
Page 9/16 


\begin{tabular}{|c|c|c|c|c|c|c|c|c|c|c|c|c|c|}
\hline Allele & D3S1358 & D1S1656 & D6S1043 & D13S317 & $\begin{array}{l}\text { PENTA- } \\
\text { E }\end{array}$ & D16S539 & D18S51 & D2S1338 & CSF1PO & $\begin{array}{l}\text { PENTA- } \\
\text { D }\end{array}$ & TH01 & vWA & D21S1" \\
\hline 5 & & & & & 0.042 & & & & & 0.001 & & & \\
\hline 6 & & & & & & 0.001 & & & & 0.002 & 0.248 & & \\
\hline 7 & & & & 0.010 & 0.094 & & & & 0.001 & 0.022 & 0.145 & & \\
\hline 8 & & 0.021 & & 0.186 & 0.011 & 0.070 & & & 0.001 & 0.021 & 0.151 & & \\
\hline 9 & & 0.005 & 0.002 & 0.079 & 0.021 & 0.142 & 0.001 & & 0.022 & 0.217 & 0.293 & & \\
\hline 9.3 & & & & & & & & & & & 0.152 & & \\
\hline 10 & & 0.011 & 0.017 & 0.110 & 0.046 & 0.081 & 0.004 & & 0.203 & 0.198 & 0.011 & 0.002 & \\
\hline 11 & & 0.185 & 0.387 & 0.241 & 0.142 & 0.360 & 0.025 & & 0.305 & 0.204 & & & \\
\hline 12 & & 0.096 & 0.186 & 0.296 & 0.107 & 0.234 & 0.099 & & 0.379 & 0.130 & & & \\
\hline \multicolumn{14}{|l|}{12.2} \\
\hline 13 & 0.001 & 0.130 & 0.082 & 0.062 & 0.075 & 0.096 & 0.137 & & 0.075 & 0.122 & & 0.006 & \\
\hline \multicolumn{14}{|l|}{13.2} \\
\hline 14 & 0.041 & 0.086 & 0.079 & 0.017 & 0.079 & 0.014 & 0.241 & & 0.011 & 0.060 & & 0.116 & \\
\hline \multicolumn{14}{|l|}{14.2} \\
\hline 15 & 0.289 & 0.161 & 0.007 & & 0.076 & 0.001 & 0.150 & 0.001 & 0.001 & 0.016 & & 0.071 & \\
\hline 15.2 & & 0.001 & & & & & & & & & & & \\
\hline 15.3 & & 0.030 & & & & & & & & & & & \\
\hline 16 & 0.302 & 0.132 & 0.005 & & 0.127 & & 0.126 & 0.007 & & 0.004 & & 0.226 & \\
\hline 16.2 & & 0.001 & & & & & & & & & & & \\
\hline 16.3 & & 0.027 & & & & & & & & & & & \\
\hline 17 & 0.233 & 0.055 & 0.035 & & 0.076 & & 0.084 & 0.076 & & 0.001 & & 0.259 & \\
\hline 17.3 & & 0.037 & & & & & & & & & & & \\
\hline 18 & 0.122 & 0.006 & 0.081 & & 0.055 & & 0.061 & 0.148 & & & & 0.209 & \\
\hline \multicolumn{14}{|l|}{18.2} \\
\hline 18.3 & & 0.011 & & & & & & & & & & & \\
\hline 19 & 0.010 & 0.001 & 0.072 & & 0.019 & & 0.050 & 0.153 & & & & 0.090 & \\
\hline 19.3 & & 0.002 & & & & & & & & & & & \\
\hline 20 & 0.001 & & 0.037 & & 0.019 & & 0.010 & 0.092 & & & & 0.020 & \\
\hline \multicolumn{14}{|l|}{20.2} \\
\hline 21 & & & 0.006 & & 0.006 & & 0.007 & 0.052 & & & & & \\
\hline \multicolumn{14}{|l|}{21.2} \\
\hline 22 & & & 0.002 & & 0.005 & & 0.005 & 0.074 & & & & & \\
\hline \multicolumn{14}{|l|}{22.2} \\
\hline 23 & & & & & & & & 0.175 & & & & & \\
\hline \multicolumn{14}{|l|}{23.2} \\
\hline 24 & & & & & & & 0.001 & 0.116 & & & & & \\
\hline \multicolumn{14}{|l|}{24.2} \\
\hline 25 & & & & & & & & 0.086 & & & & & \\
\hline 26 & & & & & & & & 0.015 & & & & & 0.007 \\
\hline \multicolumn{14}{|l|}{26.2} \\
\hline 27 & & & & & & & & 0.002 & & & & & 0.010 \\
\hline
\end{tabular}




\begin{tabular}{|lr}
\hline 28 & 0.001 \\
\hline 28.2 & 0.147 \\
\hline 29 & 0.004 \\
\hline 29.2 & 0.176 \\
\hline 29.3 & 0.005 \\
\hline 30 & 0.001 \\
\hline 30.2 & 0.191 \\
\hline 31 & 0.040 \\
\hline 31.2 & 0.024 \\
\hline 32 & 0.135 \\
\hline 32.2 & 0.005 \\
\hline 33 & 0.186 \\
\hline 33.2 & 0.001 \\
\hline 34.2 & 0.060 \\
\hline 35 & 0.006 \\
\hline 38 & 0.001 \\
\hline
\end{tabular}

\begin{tabular}{|c|c|c|c|c|c|c|c|c|c|}
\hline & PD & PE & PIC & $\mathrm{Pm}$ & TPI & GD & Hobs & Hexp & $\mathrm{pHW}$ \\
\hline D3S1358 & 0.902 & 0.453 & 0.712 & 0.098 & 1.759 & 0.755 & 0.716 & 0.754 & 0.326 \\
\hline D1S1656 & 0.971 & 0.837 & 0.871 & 0.029 & 6.266 & 0.883 & 0.920 & 0.882 & 0.419 \\
\hline D6S1043 & 0.934 & 0.577 & 0.767 & 0.066 & 2.359 & 0.789 & 0.788 & 0.788 & 0.263 \\
\hline D13S317 & 0.932 & 0.541 & 0.769 & 0.068 & 2.156 & 0.799 & 0.768 & 0.798 & 0.323 \\
\hline PENTA-E & 0.984 & 0.781 & 0.905 & 0.016 & 4.663 & 0.913 & 0.893 & 0.912 & 0.622 \\
\hline D16S539 & 0.918 & 0.546 & 0.744 & 0.082 & 2.179 & 0.775 & 0.771 & 0.774 & 0.687 \\
\hline D18S51 & 0.964 & 0.696 & 0.847 & 0.036 & 3.342 & 0.862 & 0.850 & 0.861 & 0.456 \\
\hline D2S1338 & 0.973 & 0.691 & 0.868 & 0.027 & 3.287 & 0.881 & 0.848 & 0.880 & 0.379 \\
\hline CSF1PO & 0.870 & 0.407 & 0.666 & 0.130 & 1.591 & 0.716 & 0.686 & 0.715 & 0.088 \\
\hline PENTA-D & 0.949 & 0.676 & 0.814 & 0.051 & 3.133 & 0.836 & 0.840 & 0.835 & 0.551 \\
\hline TH01 & 0.921 & 0.528 & 0.752 & 0.079 & 2.089 & 0.787 & 0.761 & 0.786 & 0.556 \\
\hline vWA & 0.935 & 0.642 & 0.784 & 0.065 & 2.824 & 0.812 & 0.823 & 0.811 & 0.559 \\
\hline D21S11 & 0.957 & 0.755 & 0.835 & 0.043 & 4.177 & 0.853 & 0.880 & 0.852 & 0.303 \\
\hline D7S820 & 0.931 & 0.541 & 0.773 & 0.069 & 2.156 & 0.803 & 0.768 & 0.802 & 0.022 \\
\hline D5S818 & 0.884 & 0.486 & 0.694 & 0.116 & 1.892 & 0.738 & 0.736 & 0.737 & 0.502 \\
\hline TPOX & 0.850 & 0.461 & 0.645 & 0.150 & 1.790 & 0.698 & 0.721 & 0.697 & 0.824 \\
\hline D8S1179 & 0.957 & 0.647 & 0.828 & 0.043 & 2.864 & 0.848 & 0.825 & 0.847 & 0.216 \\
\hline D12S391 & 0.961 & 0.657 & 0.833 & 0.039 & 2.949 & 0.850 & 0.830 & 0.849 & 0.838 \\
\hline D19S433 & 0.942 & 0.671 & 0.795 & 0.058 & 3.085 & 0.818 & 0.838 & 0.817 & 0.289 \\
\hline FGA & 0.965 & 0.705 & 0.853 & 0.035 & 3.457 & 0.869 & 0.855 & 0.868 & 0.064 \\
\hline
\end{tabular}




\begin{tabular}{|lllll|}
\hline \multicolumn{4}{|l}{ Table 4: Fst values between population of Himachal Pradesh and other geographical population group } \\
\hline Population groups & Among group variation & Among population variation & within population variation & FST \\
\hline Himachal Pradesh v/s Uttar Pradesh & 0.06 & 0.18 & 99.76 & 0.00236 \\
\hline Himachal Pradesh v/s Central India & 0.06 & 0.18 & 99.76 \\
\hline Himachal Pradesh v/s North-west India & -0.02 & 0.29 & 99.73 \\
\hline Himachal Pradesh v/s East India & -0.01 & 1.01 & 99 & 0.00242 \\
\hline Himachal Pradesh v/s South India & 0.57 & 1.05 & 98.38 & 0.01 \\
\hline Himachal Pradesh v/s East Asia & 0.82 & 0.91 & 98.27 & 0.01619 \\
\hline Himachal Pradesh v/s West Asia & -0.24 & 0.93 & 99.31 \\
\hline
\end{tabular}

\section{Figures}

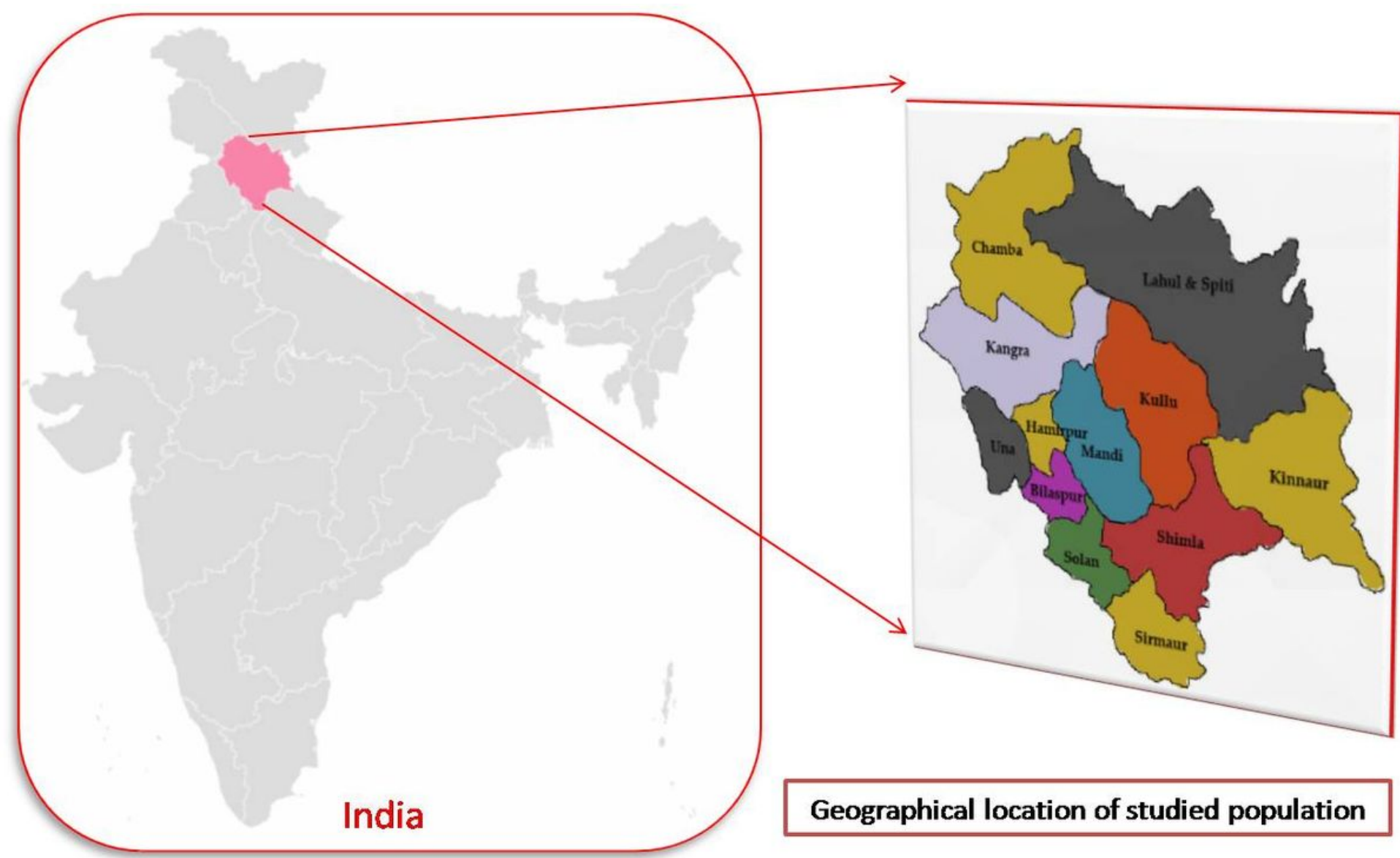

Figure 1

Geographical location of the studied population. Note: The designations employed and the presentation of the material on this map do not imply the expression of any opinion whatsoever on the part of Research Square concerning the legal status of any country, territory, city or area or of its authorities, or concerning the delimitation of its frontiers or boundaries. This map has been provided by the authors. 


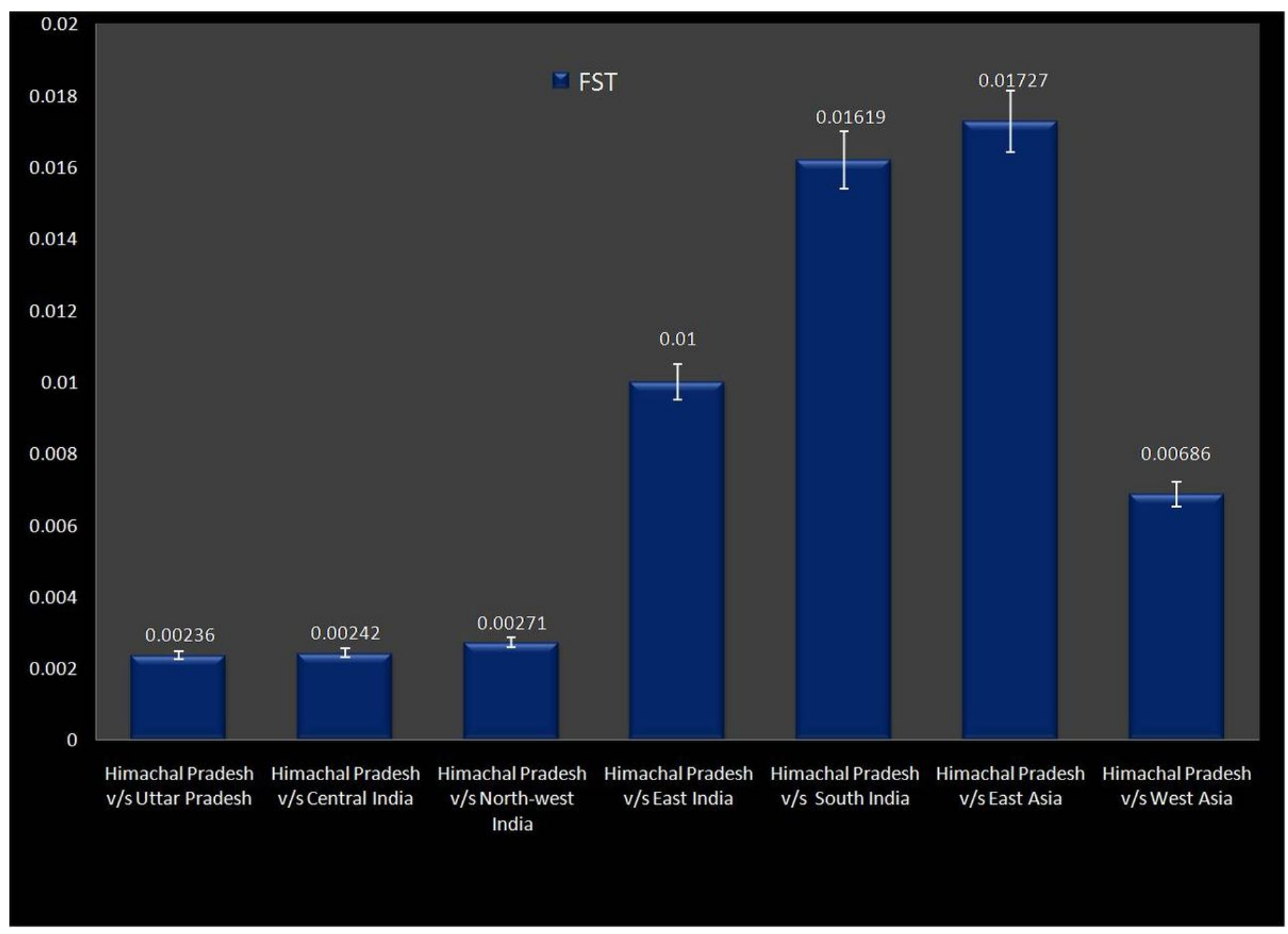

\section{Figure 2}

Fst values between the population of Himachal Pradesh and other ethnic groups. 


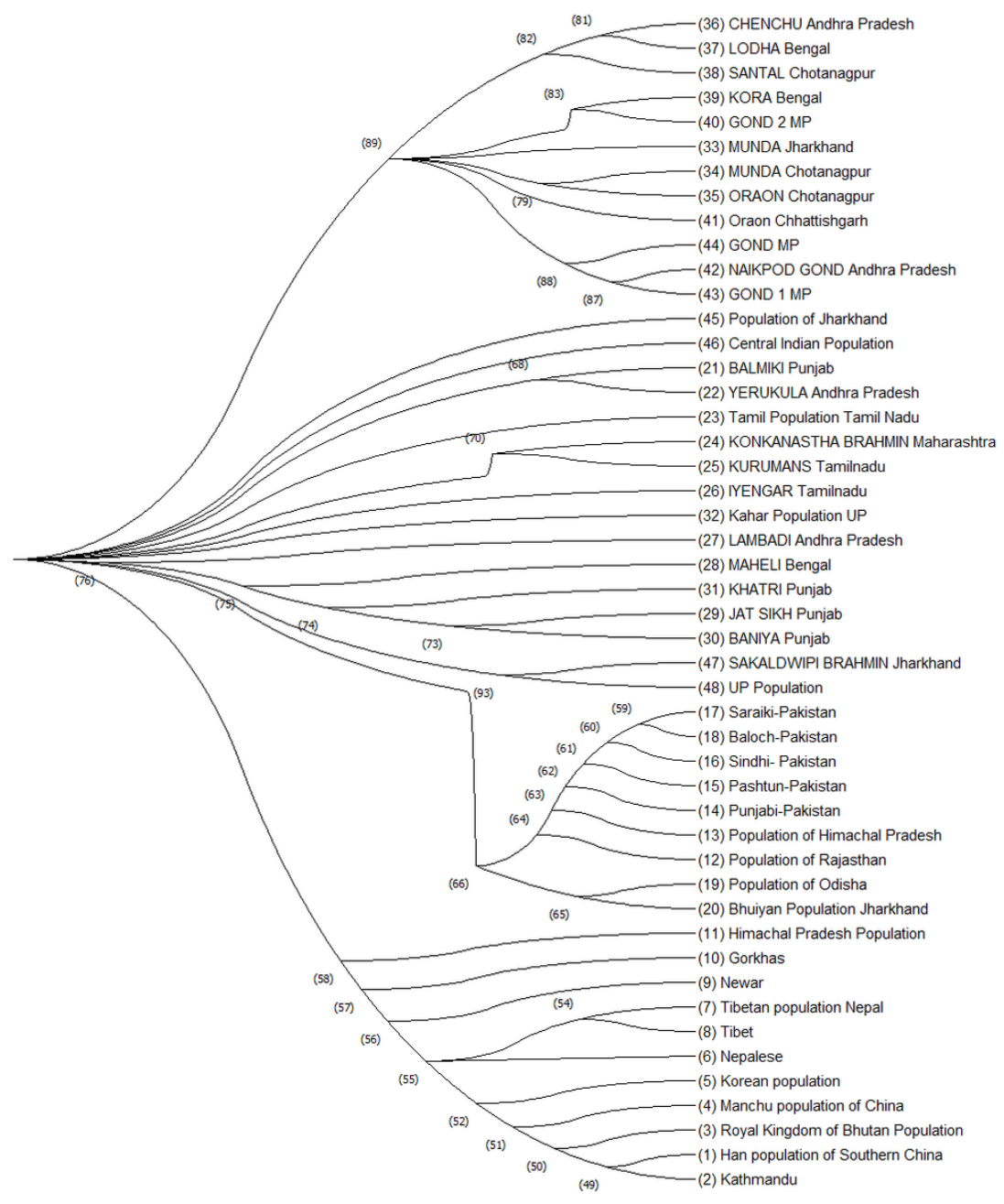

\section{Figure 3}

Phylogenetic tree constructed using POPTREE based on Nei's DA distance of 15 autosomal STRs in the population of Himachal Pradesh and 47 other populations.
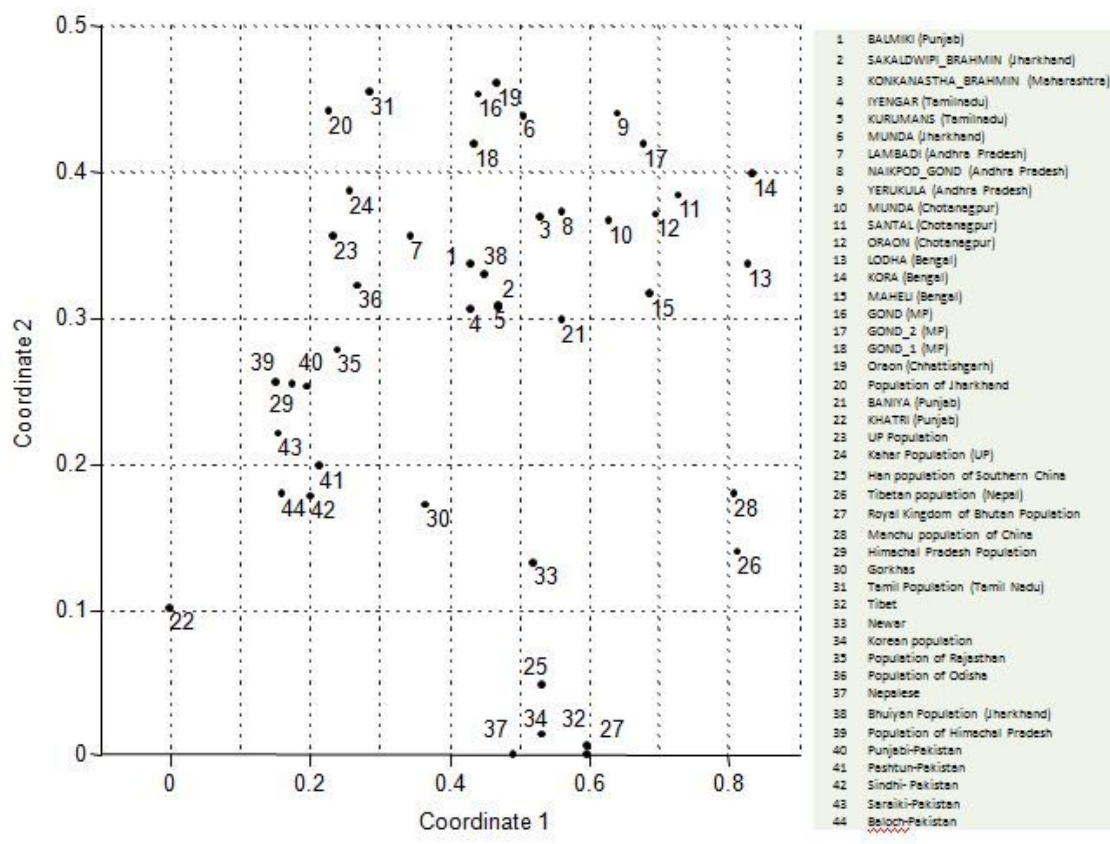

Figure 4 
Principal Coordinate Analysis (PCoA) plot constructed from Nei's DA distance of 15 autosomal STRs after removal of outlier populations

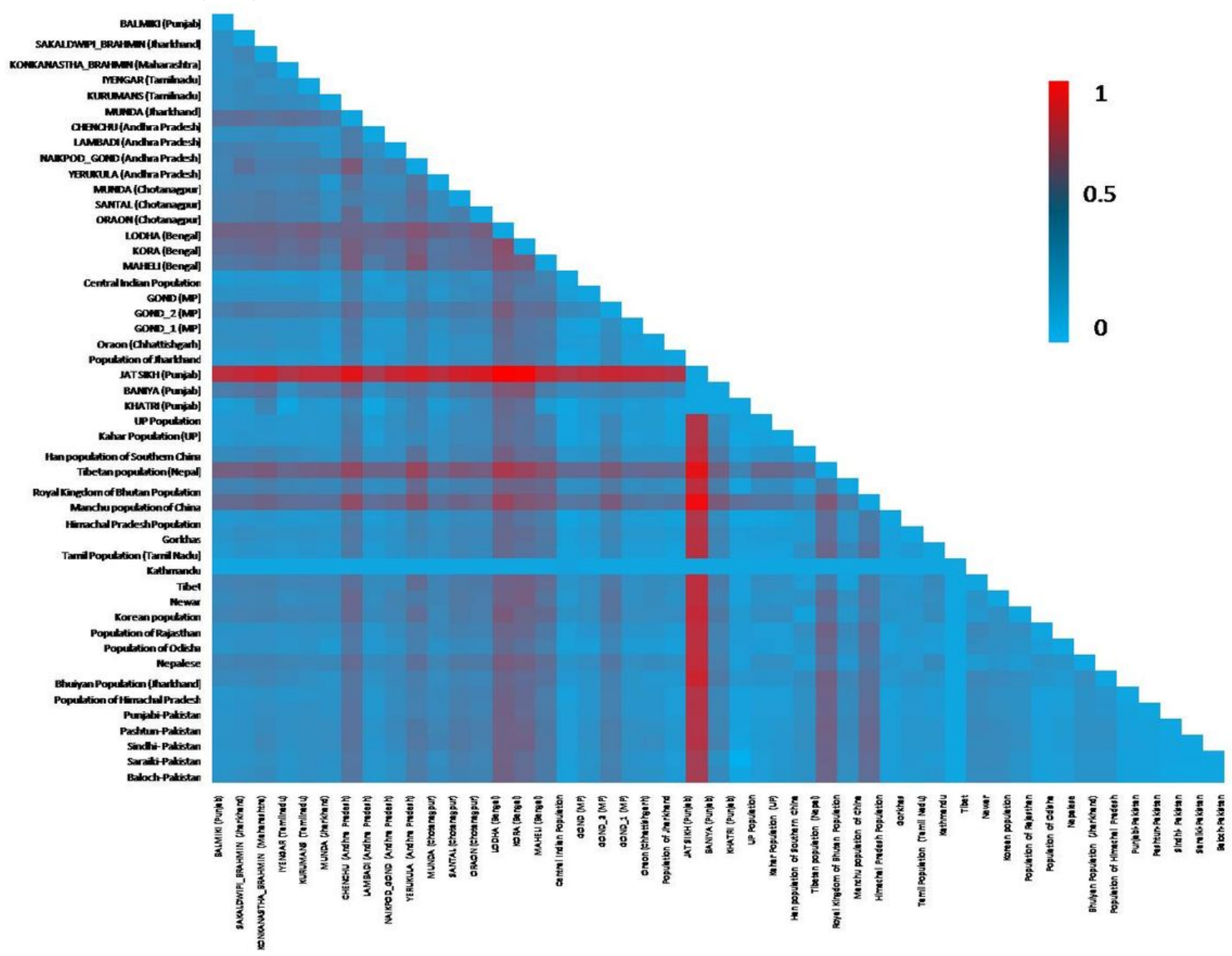

Figure 5

Graphical presentation of comparative Fst values of the studied and compared 47 Asian populations. 


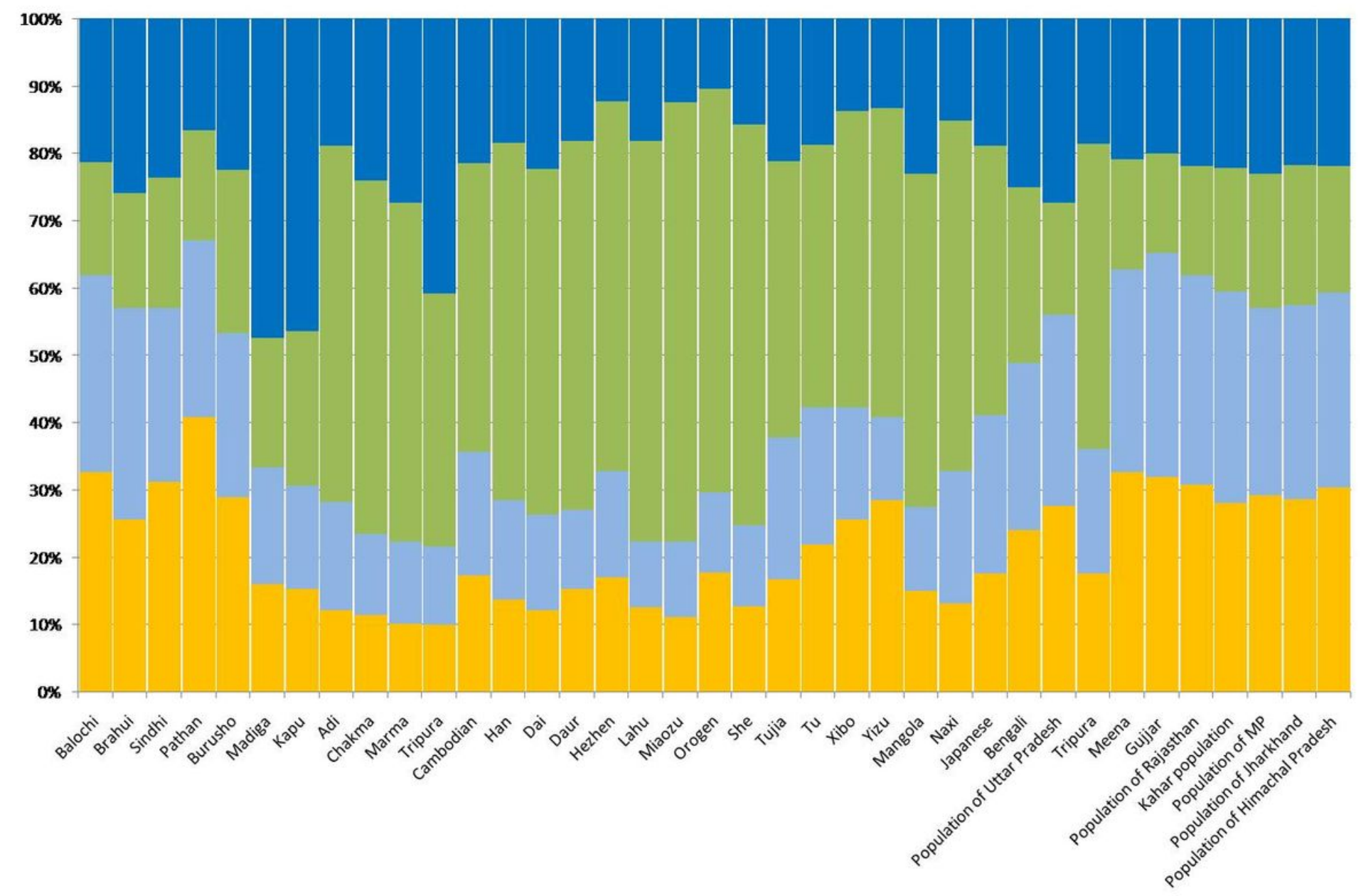

\section{Figure 6}

Population genetic structure of 37 Asian (western, southern, eastern, south-eastern) populations based on 15 autosomal STR markers ( $k=4)$.

\section{Supplementary Files}

This is a list of supplementary files associated with this preprint. Click to download.

- Fig.S1.pdf 